\title{
Can Tinted Lenses Be Used to Manipulate Pupil Size and Visual Performance When Wearing Multifocal Contact Lenses?
}

This article was published in the following Dove Press journal: Clinical Optometry

\author{
Hyung Min Park (D) \\ Young Uk Ryu ${ }^{2}$ \\ Inn-Jee Park' \\ Byoung Sun Chu $\mathbb{D I}^{\prime}$ \\ 'School of Optometry and Vision \\ Science, Daegu Catholic University, \\ Gyeongsan-si, Republic of Korea; \\ 2Department of Physical Therapy, Daegu \\ Catholic University, Gyeongsan-si, \\ Republic of Korea
}

Correspondence: Byoung Sun Chu

School of Optometry and Vision Science, Daegu Catholic University, 13-13 Hayangro, Hayang-eup, Gyeongsan-si,

Gyeongsangbuk-do 38430, Republic of Korea

Tel +82-53-850-2553

Fax +82-53-359-6793

Email bschu@cu.ac.kr
Background: The purpose of this study is to investigate the effect of wearing neutral density (ND) filters with different transmittance levels over multifocal contact lenses (MTF CLs) on pupil size, visual functions and the dynamic accommodative response under daylight conditions in early presbyopes.

Methods: Seventeen individuals aged between 40 and 48 years (mean age $42.35 \pm 2.62$ years) were recruited to participate in this study. This study involved a repeated-measures design with two within-subject factors: optical condition (which had five levels), and fixation distance (which had three levels). The five optical conditions were no correction (baseline), MTF CL wear, MTF CL wear +0.3 ND filter (transmission $[\mathrm{Tv}]=48.38 \%$ ), MTF CL wear $+0.6 \mathrm{ND}$ filter $(\mathrm{Tv}=27.12 \%)$ and MTF CL wear +0.9 ND filter $(\mathrm{Tv}=14.58 \%)$. The three fixation distances were $3 \mathrm{~m}, 40 \mathrm{~cm}$ and $20 \mathrm{~cm}$. Outcome measures were pupil size, the measured accommodative response (optical aid + physiological accommodation), distance visual acuity (VA), near VA and contrast sensitivity (CS). Results: There was no effect of optical condition on the accommodative response; however, there was a significant effect of fixation distance. (Accommodative response was $0.44 \pm 0.29$, $1.83 \pm 0.37$ and $4.03 \pm 0.46 \mathrm{D}$ for fixation distances of $3 \mathrm{~m}, 40 \mathrm{~cm}$ and $20 \mathrm{~cm}$, respectively; $\mathrm{p}<0.05$.) There was a significant effect of optical condition $(p<0.05)$ and of fixation distance on pupil size variation $(5.13 \pm 0.90 \mathrm{~mm}$ for $3 \mathrm{~m}, 4.71 \pm 0.92 \mathrm{~mm}$ for $40 \mathrm{~cm}$ and $4.11 \pm 1.04 \mathrm{~mm}$ for $20 \mathrm{~cm} ; p<0.05$ ). Optical condition had a significant effect on distance VA, near VA and CS $(p<0.05)$. Compared to the reduction in distance VA, near VA was relatively small (two-letter reduction with $0.9 \mathrm{ND}$ ) and unlikely to be clinically significant.

Conclusion: This study demonstrated that in a group of adults with early presbyopia, the use of ND filters enlarged pupil size. However, the combination of enlarged pupils and MTF CL did not improve distance vision, and if transmittance was reduced by $50 \%$ it resulted in decrements in vision and CS. MTF CL designs which incorporate tints, or tints that vary in darkness in response to ultraviolet exposure, should consider these findings.

Keywords: multifocal contact lens, pupil size, tinted lens, accommodative responses, vision

\section{Introduction}

Worldwide, the proportion of people aged over 45 years increased from $26.5 \%$ in 2010 to $30.0 \%$ in 2019 , and is projected to reach $33.5 \%$ in $2030 .{ }^{1}$ Associated with this demographic transition toward an ageing population, the number of people with presbyopia will increase worldwide. Presbyopia is a normal physiological change that often becomes problematic in adults after about 45 years of age, with the exact onset depending on a range of factors such as individual refractive error, ${ }^{2}$ climate and geographic location. ${ }^{3}$ 
Presbyopia is caused by a reduction of accommodative ability due to the loss of elasticity of the crystalline lens, resulting in a reduction in the clarity of near vision. ${ }^{4}$

Studies have found that a lack of adequate correction for presbyopia has negative effects on health-related quality of life when measured by a self-administered questionnaire, the National Eye Institute Refractive Error Quality of Life (NEI-RQL) instrument. ${ }^{5}$ Tasks such as driving may also be hampered by uncorrected presbyopia, ${ }^{6}$ with safety ramifications. Therefore, appropriate correction of focus for presbyopia is important.

Of the non-surgical options for presbyopia, progressive addition lens spectacles (37\% of presbyopes) and bifocal spectacles (16\% of presbyopes) are still the most commonly worn corrections. ${ }^{7}$ Over the past decade, multifocal contact lenses (MTF CLs) have been the fastest growing presbyopic correction, with MTF CL prescribing increasing from $5 \%$ in 2005 to $13 \%$ in $2019 .{ }^{8}$ When only considering presbyopes, $25 \%$ of lenses fitted were MTF CLs in 2005 , increasing to approximately $40 \%$ in $2019 .^{8}$

It has also been suggested that the use of contact lenses for correcting presbyopia will continue to increase with advances in contact lens technology and the likelihood that non-presbyopes who currently prefer to wear contact lenses will continue to want to wear contact lenses as they become the next generation of presbyopes. ${ }^{9,10}$

The optical design of MTF CLs is not as simple as for spherical contact lenses, and therefore prescribing to optimize visual performance requires a more nuanced approach than for single vision correction. Simultaneous design MTF CLs use near and distance optic zones which are located within the entrance pupil, enabling partial focus of near and distant objects at the same time. ${ }^{11}$ The in-focus image is present simultaneously with the out-of-focus image, resulting in a reduction in the contrast of the focused image. ${ }^{12,13}$ Woods et al found that wearing MTF CLs resulted in significantly poorer distance and near high- and low-contrast visual acuities compared to monovision, in which one eye is corrected for distance and the fellow eye is corrected for near using spherical or toric contact lenses, ${ }^{14}$ despite higher subjective satisfaction with the MTF CL correction modality. ${ }^{13}$

The extent of visual performance reduction for simultaneous design MTF CLs is dependent on the relative amounts of in-focus to out-of-focus image on the retina and is closely related to pupil size. ${ }^{15}$ For instance, when wearing a centrenear design and when the pupil is small, distance vision will be less clear than near vision. On the other hand, when the pupil is large, proportionally more light will pass through the distance viewing portion than the near viewing portion, which may result in compromised near vision.

As MTF CLs are recognized to be more optically complex to prescribe, manufacturers have provided fitting guidelines for clinicians that explain the adjustment of MTF CL prescriptions to improve near or distance vision, for example by changing spherical power or the magnitude of the near addition for the dominant or non-dominant eye. However, this refraction adjustment is typically only conducted during a clinical consultation, and not in the patient's real-life situation. For instance, there may be reduction of distance vision under bright conditions during the daytime when wearing centre-near MTF CLs due to constricted pupils. There have been anecdotal suggestions that one way to improve distance vision temporarily when required may be to wear tinted lenses, for example sunglasses, simultaneously to reduce incoming light to make the pupil size larger. However, it is not known whether wearing tinted lenses over MTF CLs improves blurred distance vision in MTF CL wearers in daylight conditions. To shed some light on this question, the aim of this study was to investigate the effect of wearing neutral density (ND) filters with different transmittance levels over MTF CLs on pupil size, visual functions and the dynamic accommodative response under daylight conditions in early presbyopes.

\section{Methods}

\section{Participants}

Inclusion criteria were: 1) aged 40 years and above, to capture participants with early presbyopia; ${ }^{16}$ (2) unaided visual acuity (VA) better than 6/9 (0.2 logMAR) in each eye; (3) no ocular pathology and no previous ocular surgery by self-report; (4) age-normal range of binocular visual function, such as accommodative amplitude defined by the Hofstetter formula assessed by the push-up method; and (5) previous or current contact lens wearer. Written Informed consent was obtained from all participants, and this study was conducted in accordance with the Declaration of Helsinki. The research protocol was approved by the Daegu Catholic University Institutional Review Board. All participants were screened for their suitability to participate in the study by clinical examination.

\section{Neutral Density (ND) Filters and Multifocal Contact Lenses}

In designing the study, two possible approaches were considered: to use commercially available sunglasses or ND 
filters. Commercially available sunglasses were not used as there is much variation in the spectral transmittance of lenses on the market, which may complicate the interpretation of findings, and we wished to establish the relationship between transmittance, pupil size and vision. One limitation of the approach taken is that the results may not be directly translatable to sunglasses wear as commercially available sunglasses have a requirement to reduce ultraviolet (UV) light transmittance, whereas ND filters do not, so this limitation will be considered in the discussion. To simulate the wearing of tinted lenses in a controlled manner, three different ND filters were cut and fitted into spectacle frames. These ND filters were 0.3, 0.6 and 0.9 ND (Cotech, UK) and their light transmittance values, as measured by a spectrometer (Evolution 201; USA), were $\mathrm{Tv}=48.38 \%$, $27.12 \%$ and $14.58 \%$, respectively (Figure 1 ).

The MTF CLs used in the study were soft contact lenses for daily disposable wear (delefilcon A, 33\% water) with simultaneous centre-near design where the maximum plus power was in the centre of the lens (near correction), progressing to more minus (distance correction) in the periphery of the optical zone. All participants were fitted with plano power for distance and high addition power (minimum addition from +2.25 to +2.50 from the manufacturer's fitting guide). Although it is acknowledged that the distance corrections were not optimized for each participant, the group mean unaided VA was better than $6 / 6(0.00 \log M A R)$.

\section{Dynamic Accommodation Response and Pupil Size Measurement}

The WAM-5500 Binocular Accommodation Auto Ref/ Keratometer (Grand Seiko, Japan) was used to measure the dynamic pupil diameter (in $0.1 \mathrm{~mm}$ steps) and dynamic accommodative response (spherical equivalent) at $6 \mathrm{~Hz}$. Since the WAM-5500 instrument is an open viewing window instrument, fixation target and fixation distance can be varied easily, so that measurements were taken while the participant fixated on a target located at three different distances: $3 \mathrm{~m}$ ( $0.33 \mathrm{D}$ of accommodative stimulus), $40 \mathrm{~cm}$ (2.50 D of accommodative stimulus) and $20 \mathrm{~cm}(5.00 \mathrm{D}$ of accommodative stimulus) for 5 seconds. The accommodative response in this study was defined as the spherical equivalent refractive error measured by the WAM-5500 instrument when fixating at different distance targets, which was $0.2 \log$ MAR letter.

\section{Visual Function Measurement}

For visual functions, the Early Treatment Diabetic Retinopathy Study (ETDRS) chart was used to measure distance VA, a Near VA test chart (Lighthouse International, USA) was used to measure near VA and the Mars Numeral Contrast Sensitivity Chart (Mars chart; Mars Perceptrix, Chappaqua, NY, USA) was used to measure CS at $50 \mathrm{~cm}$. The Mars chart uses stimuli that subtend 2 degrees of visual angle and provides CS as $\log C S$. All visual function measurements were conducted binocularly.

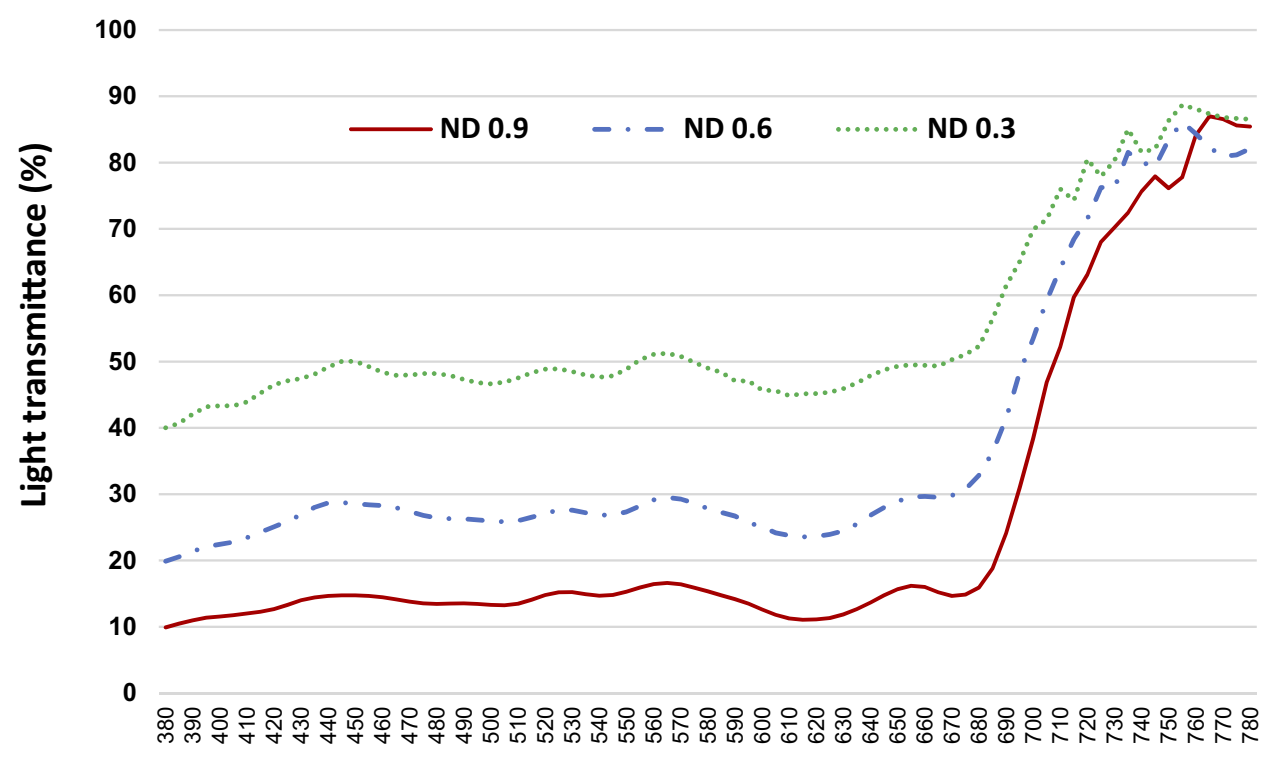

Wavelength $(\mathrm{nm})$

Figure I Visible light transmittance $(380-740 \mathrm{~nm})$ of ND filters used for the study. 


\section{Measurement Conditions}

This study utilized a repeated-measures design using two within-subjects factors: optical condition and fixation distance. The optical condition factor had five levels: no correction (baseline), multifocal contact lens wear, MTF CL wear +0.3 ND filter, MTF CL wear +0.6 ND filter and MTF CL wear +0.9 ND filter. There were three assessed fixation distances: $3 \mathrm{~m}, 40 \mathrm{~cm}$ and $20 \mathrm{~cm}$. All measurements, including the dynamic accommodative response, pupil size changes and visual functions (VA and CS), were measured under the five conditions. For consistent lighting conditions, measurements were taken in the same laboratory, where the overhead light was turned on, giving a room illumination of 550 lux (TES-1330A; TES Electrical Electronic Corp, Taiwan). These lighting conditions were used to simulate as closely as possible invehicle conditions during the daytime. Data were analysed using repeated-measures ANOVA.

\section{Results}

\section{Participants}

Seventeen individuals aged between 40 and 48 years (mean age $42.35 \pm 2.62$ years, ten males and seven females) were recruited to participate in this study. Their baseline unaided mean amplitudes of accommodation were $6.82 \pm 0.51 \mathrm{D}$ and $6.58 \pm 0.52 \mathrm{D}$ for right and left eyes, respectively, which were within the normal range defined by the Hofstetter equation for this age range. Pupil sizes under photopic conditions were $4.46 \pm 0.19$ and $4.32 \pm 0.17 \mathrm{~mm}$. Mean spherical equivalents of participants were $-0.17 \pm 0.23$ and -0.16 \pm 0.37 for right and left eyes, respectively. VA values without correction were $-0.05 \pm 0.02$ and $0.03 \pm 0.01 \log \mathrm{MAR}$ for distance and near, respectively. CS measured by the Mars chart was $1.74 \pm 0.03 \log C S$ (Table 1). Overrefraction for each condition is presented in Table 2.

\section{Accommodative Response for Three Fixation Distances While Wearing the Multifocal Contact Lenses and ND Filter}

Mean accommodative responses for three fixation distances under varying test conditions are presented in Figure 2. Dynamic accommodative responses for different fixation distances under different conditions measured for 5 seconds $(6 \mathrm{~Hz})$ are presented in Figure 3. There was no effect of optical condition type $(F(4,13)$ $=0.93, p=0.47$ ) but there was a significant effect of the fixation distance, hence, dioptric accommodative stimulus $(F(2,15)=1274.23, p<0.0001)$. The accommodative response was larger with increasing accommodative stimulus magnitude $(p<0.0001)$.

\section{Pupil Size for Three Fixation Distances While Wearing the Multifocal Contact Lenses and ND Filter}

Both optical condition $(F(4,13)=45.89, p<0.0001)$ and fixation distance $(F(2,15)=13.85, \quad p<0.0001)$ had a significant effect on pupil size. Pairwise comparison, with Bonferroni correction, indicated that the optical conditions of no correction and MTF CL correction did not significantly differ in pupil size, but that all conditions that included ND filters resulted in significantly larger pupil size than no correction and only MTF CL wear. For each darker ND filter, pupil size was significantly larger in magnitude $(p \leq 0.014)$. Pupil size was significantly smaller

Table I Baseline Measurements (No Correction)

\begin{tabular}{|l|l|l|l|l|l|l|l|}
\hline $\begin{array}{l}\text { Baseline Measurement } \\
\text { (Unaided) }\end{array}$ & \multicolumn{2}{l|l}{$\begin{array}{l}\text { Amplitude of } \\
\text { Accommodation } \\
\text { (D) }\end{array}$} & $\begin{array}{l}\text { Pupil Size Under } \\
\text { Photopic } \\
\text { Condition (mm) }\end{array}$ & $\begin{array}{l}\text { Distance } \\
\text { VA } \\
\text { (LogMAR) }\end{array}$ & $\begin{array}{l}\text { Near VA } \\
\text { (LogMAR) }\end{array}$ & $\begin{array}{l}\text { Contrast Sensitivity } \\
\text { (Log) }\end{array}$ \\
\cline { 2 - 8 } & OD & OS & OD & OS & OU & OU & OU \\
\hline Mean \pm SD & $\begin{array}{l}6.82 \\
\pm 0.51\end{array}$ & $\begin{array}{l}6.58 \\
\pm 0.52\end{array}$ & $\begin{array}{l}4.46 \\
\pm 0.19\end{array}$ & $\begin{array}{l}4.32 \\
\pm 0.17\end{array}$ & $-0.05 \pm 0.02$ & $0.03 \pm 0.01$ & $1.74 \pm 0.03$ \\
\hline
\end{tabular}

Table 2 Mean Overrefraction of Both Eyes (Spherical Equivalent) for Each Condition

\begin{tabular}{|l|l|l|l|l|l|}
\hline & $\begin{array}{l}\text { Baseline } \\
\text { (No Correction) }\end{array}$ & Multifocal CL & $\begin{array}{l}\text { Multifocal CL } \\
+\mathbf{0 . 3} \text { ND }\end{array}$ & $\begin{array}{l}\text { Multifocal CL } \\
+\mathbf{0 . 6} \text { ND }\end{array}$ & $\begin{array}{l}\text { Multifocal CL } \\
+\mathbf{0 . 9} \text { ND }\end{array}$ \\
\hline Mean \pm SD & $-0.16 \pm 0.24$ & $-0.22 \pm 0.32$ & $-0.29 \pm 0.29$ & $-0.31 \pm 0.37$ & $-0.32 \pm 0.41$ \\
\hline
\end{tabular}



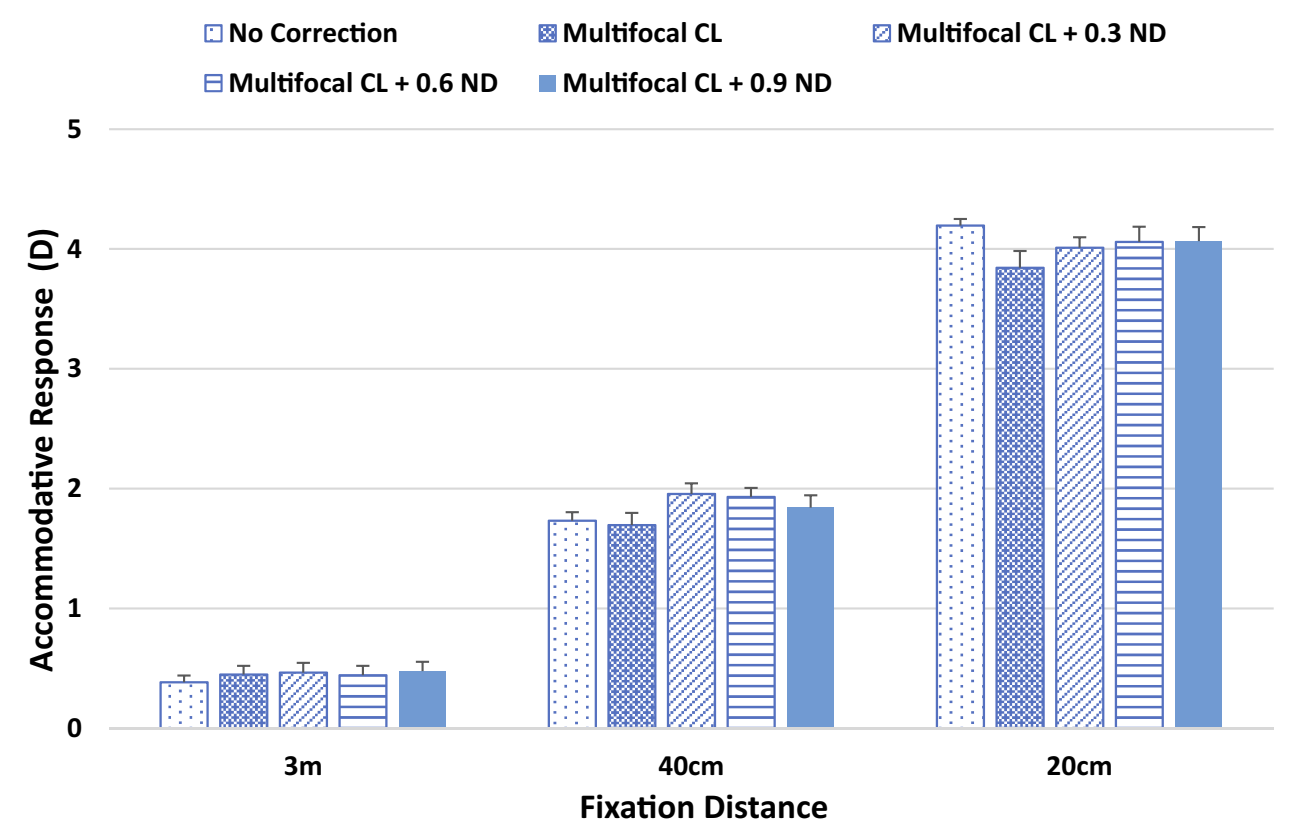

Figure 2 Mean accommodative response for different fixation distances under different conditions.

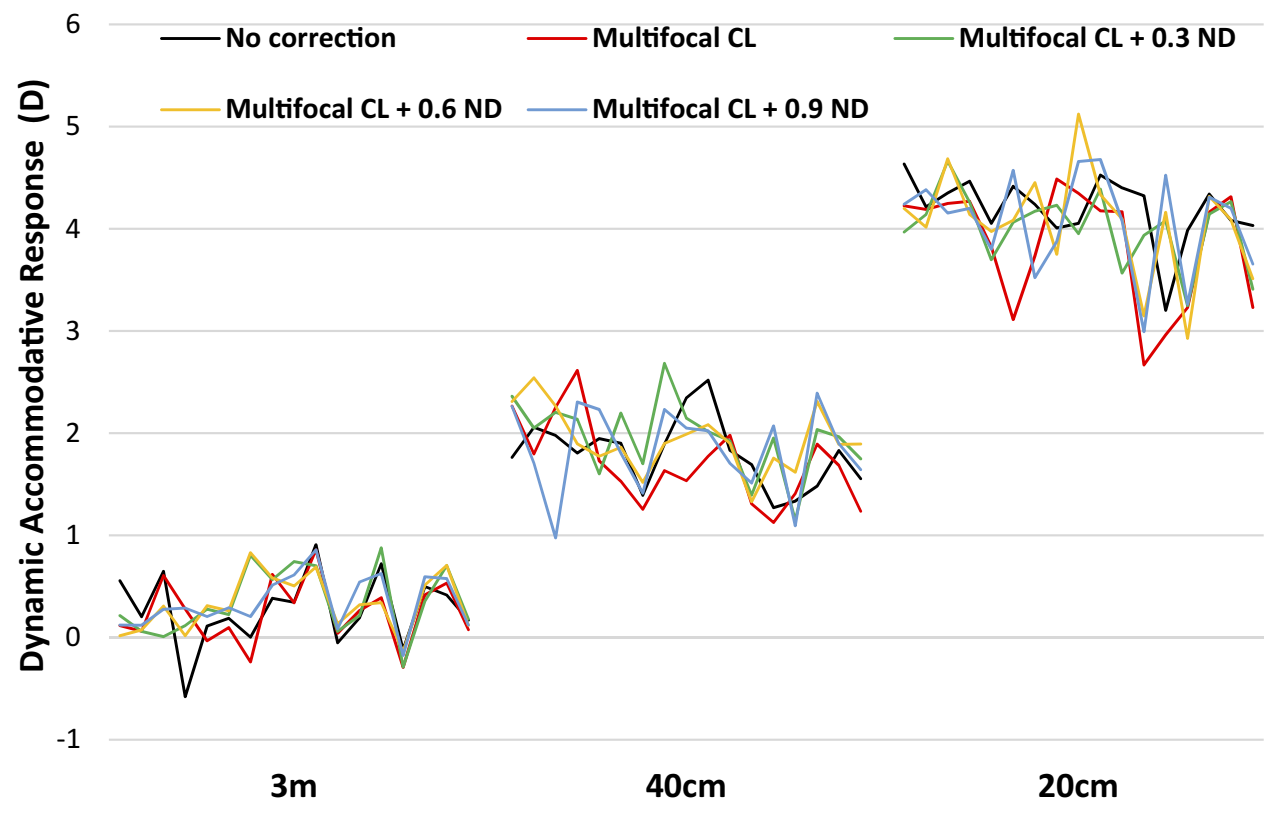

Figure 3 Dynamic accommodative response for different fixation distances under different conditions measured for 5 seconds.

for each shorter fixation distance $(p \leq 0.001)$ (Figure 4). Dynamic pupil size variation during 5 seconds of measurement is presented in Figure 5.

\section{Visual Functions}

All visual function results are presented in Table 3.

The repeatability of distance logMAR VA in adults has been reported to be at best $\pm 0.07 \log \mathrm{MAR},{ }^{17}$ or about seven letters; hence, although statistically significant, the clinically significant distance VA findings are likely to be for the optical conditions $1<4$ and 5 and $2<5$.

Optical condition had a significant effect on distance VA measured using a high-contrast letter chart $(F(4,13)$ $=43.34, p<0.0001)$. Pairwise comparison revealed that distance VA became poorer with MTF CL wear and ND filter wear $(p<0.001)$. Although there was no 


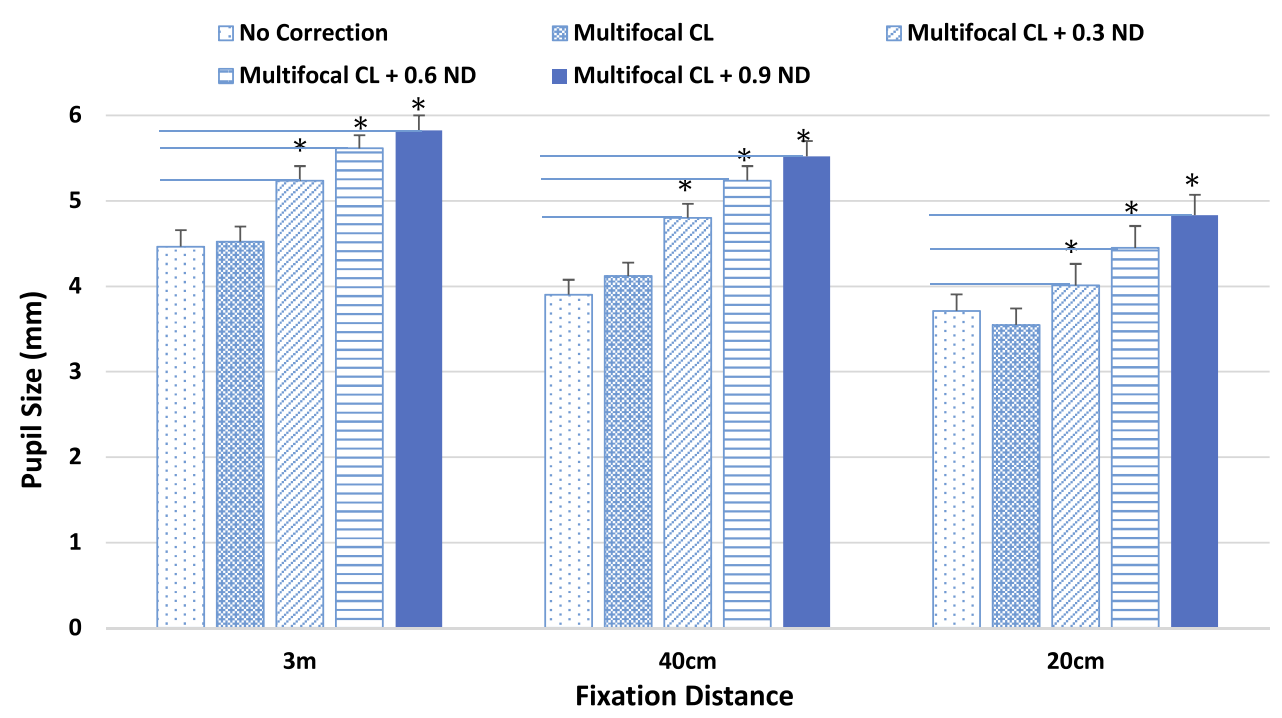

Figure 4 Mean pupil size for different fixation distances under different conditions $\left({ }^{*} p<0.05\right)$.

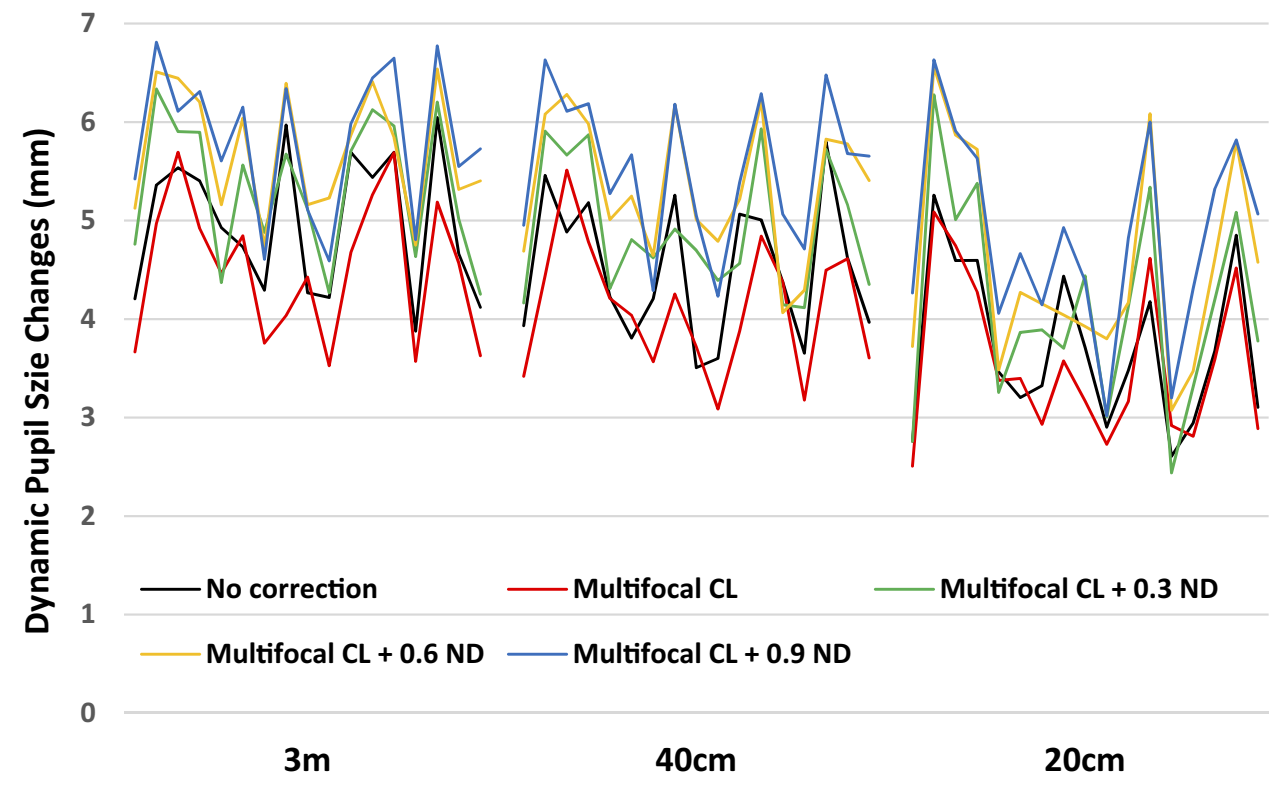

Figure 5 Dynamic pupil size changes for different fixation distances under different conditions measured for 5 seconds.

difference between MTF CL and MTF CL with 0.3 ND, VA became worse the lower the transmittance of the ND filter $(p<0.001)$.

Optical condition had a significant effect on near VA $(F$ $(4,13)=4.15, p=0.02)$. Pairwise comparison indicated that MTF CL and 0.9 ND resulted in significantly poorer near VA than MTF CL alone and MTF CL with 0.3 ND.

Optical condition had a significant effect on CS measured using the Mars letter chart $(F(4,13)=53.42$, $p<0.0001)$. Pairwise comparison revealed that CS became poorer with MTF CL worn $(p<0.05)$ and CS reduction become greater with less transmittance of ND filter worn $(p<0.05)$.

\section{Discussion}

It is well known that pupil size is associated with accommodation and that the pupil constricts when accommodation occurs. ${ }^{18,19}$ The accommodative reflex occurs with changes in fixation distance such as far to near or vice versa.

This study investigated the accommodative response with different pupil size induced by wearing ND filters at 
Table 3 Visual Function Measures with Different ND Filters (mean $\pm S D, m m$ )

\begin{tabular}{|c|c|c|c|c|c|c|c|}
\hline $\begin{array}{l}\text { Accommodative } \\
\text { Stimulus (D) }\end{array}$ & $\begin{array}{l}\text { I. Baseline } \\
\text { (No } \\
\text { Correction) }\end{array}$ & $\begin{array}{l}2 . \\
\text { Multifocal } \\
\text { CL }\end{array}$ & $\begin{array}{l}3 . \\
\text { Multifocal } \\
\text { CL } \\
+0.3 \text { ND }\end{array}$ & $\begin{array}{l}4 . \\
\text { Multifocal } \\
\text { CL } \\
+0.6 \mathrm{ND}\end{array}$ & $\begin{array}{l}5 . \\
\text { Multifocal } \\
\text { CL } \\
+0.9 \mathrm{ND}\end{array}$ & ANOVA & $\begin{array}{l}\text { Significant } \\
\text { Difference Between the } \\
\text { Following Optical } \\
\text { Conditions }(p<0.05)\end{array}$ \\
\hline $\begin{array}{l}\text { Distance VA } \\
\text { (LogMAR) }\end{array}$ & $-0.05 \pm 0.10$ & $0.10 \pm 0.04$ & $0.11 \pm 0.05$ & $0.20 \pm 0.06$ & $0.25 \pm 0.10$ & $\begin{array}{l}F(4,13) \\
=43.34 \\
p<0.0001\end{array}$ & $\begin{array}{l}I<2,3,4,5 \\
2<45 \\
3<4,5\end{array}$ \\
\hline Near VA (LogMAR) & $0.03 \pm 0.04$ & $0.02 \pm 0.04$ & $0.02 \pm 0.03$ & $0.04 \pm 0.03$ & $0.06 \pm 0.03$ & $\begin{array}{l}F(4,80) \\
=4.63 \\
p<0.05\end{array}$ & I, $2,3<5$ \\
\hline $\begin{array}{l}\text { Contrast Sensitivity } \\
\text { (Log CS) }\end{array}$ & $1.74 \pm 0.03$ & $1.56 \pm 0.18$ & $1.34 \pm 0.16$ & $1.14 \pm 0.17$ & $0.93 \pm 0.20$ & $\begin{array}{l}F(4,80) \\
=63.8, \\
p<0.001\end{array}$ & $\begin{array}{l}1<2,3,4,5 \\
2<3,4,5 \\
3<4,5 \\
4<5\end{array}$ \\
\hline
\end{tabular}

three fixation distances. A study by Simmers et al found no difference in the accommodative response with varying colour-tinted lenses (prescribed tinted lens for individual, tinted lens of complementary colour and ND filter) of different transmittance of lens (ranging from 5.6\% to $23.7 \%$ ) compared with no tinted lenses. They also pointed out that microfluctuations were greater with no tinted lenses. ${ }^{20}$ Similarly, Ciuffreda et al showed no significant difference of mean levels of accommodation between spectrally broadband filtered lenses (Irlen lenses) and non-filtered lenses. ${ }^{21}$ Our study essentially supports these previous findings. In other words, the measured accommodative response at a given fixation distance was found to be similar regardless of the ND filter worn and fluctuations in pupil size in MTF CL wear.

These findings must be interpreted keeping in mind the fact that some of the accommodative response measured must have been supplied by the MTF CL, and is not due to accommodation by the participants' own crystalline lens. Thus, participants accommodated only as necessary. As the near addition was +2.25 to $+2.50 \mathrm{D}$, this should have resulted in the participants exerting none of their own accommodation for the $40 \mathrm{~cm}$ fixation distance, but about 2.50 D of their own accommodation on top of the presbyopic addition for the $20 \mathrm{~cm}$ fixation distance. Previous studies have shown that presbyopes prefer to have some accommodation in reserve; Millodot and Millodot estimated this preference to be highly variable $(50.68 \pm 27.2 \%$ (SD) in presbyopes $<52$ years of age) and decreasing for shorter working distances. ${ }^{22}$ Even presbyopes who wear monovision contact lens prescriptions, one eye corrected for distance vision and one eye for near vision, are variable in their accommodative response; some accommodate their distance-prescribed eye whereas some actively switch eye depending on the viewing distance. $^{23}$ Variability in accommodative strategies to achieve clarity may explain why participants, even with the near addition supplied by the MTF CLs, still showed lags of accommodation of up to $1 \mathrm{D}$.

In this study, dynamic accommodation was only recorded for 5 seconds, rather than for an extended period of time, so it is possible that with extended reading, fatigue may set in for the $20 \mathrm{~cm}$ condition. Considering that contact lenses are now being developed to darken in response to UV light, ${ }^{24}$ these findings will be relevant if the same technology is applied to MTF CL designs in the future. As stated earlier, the ND filters did not specifically filter out UV light, which is why they are not exactly equivalent to sunglasses lenses. With the exception of the UV filter condition, the spectral transmittance profile is as would be expected for fashion-tinted or sunglasses lenses, which are designed to filter all wavelengths approximately equally, such as grey lenses. It is possible that using different wavelengths of light may affect the pupil response, and this requires further investigation. However, UV light is not part of the visible light spectrum and does not result in pupillary responses, ${ }^{25}$ so the use of ND filters rather than sunglasses (which include UV filters) will not affect the pupil measurement considerations. Therefore, the effects of sunglasses and ND filters on pupil 
size and accommodative response are likely to be similar as long as the transmittance is similar.

This study clearly demonstrated that pupil size can be varied when wearing different levels of ND filter under bright lighting conditions. In addition, pupil constriction when viewing closer objects was demonstrated.

Several studies have pointed out that pupil size variation is an important factor when prescribing MTF CLs. $^{26,27}$ Lanier et al showed that when $4 \mathrm{~mm}$ of pupil was induced, high-contrast visual acuity (HCVA) at distance became worse with the centre-near lens compared to wearing single vision correction. ${ }^{28}$ In addition, Lanier et al reported similar HCVA measures with 4 and $6 \mathrm{~mm}$ pupil sizes when wearing centre-near MTF CL designs. ${ }^{28}$ In the present study, no improvement was found in HCVA by increasing pupil size through a mechanism of reducing light transmittance to the macula. Although there was no additional reduction in VA when wearing 0.3ND over the MTF CLs, there was a reduction in VA when wearing 0.6 and $0.9 \mathrm{ND}$ despite increased pupil sizes. Considering the findings of Lanier et al, that $6 \mathrm{~mm}$ pupils are beneficial and $4 \mathrm{~mm}$ are detrimental to HCVA, ${ }^{28}$ examination of Figure 5 reveals that the average pupil size was smallest for the no contact lens and MTF CL corrections, and hence more likely to drop below $4 \mathrm{~mm}$ for the distance viewing task for those two optical conditions. The MTF CL correction was found to result in significantly poorer distance VA compared with no correction, which agrees with Lanier et al, ${ }^{28}$ that HCVA with centre-near lenses can result in decrements to distance vision due to their design. Charman plotted the percentage of pupil area covered by near correction with centre-near bifocal contact lenses and showed that approximately $50 \%$ of near correction is covered with $4 \mathrm{~mm}$ of pupil size and approximately $30 \%$ and $20 \%$ of near correction is covered with 5 and $6 \mathrm{~mm}$ of pupil size, respectively. ${ }^{15}$ Differences in pupil size between no correction and the $0.9 \mathrm{ND}$ filter in the study were $1.36,1.62$ and $1.12 \mathrm{~mm}$ with $3 \mathrm{~m}, 40 \mathrm{~cm}$ and $20 \mathrm{~cm}$ fixation distance, respectively, and therefore there may be around $20-30 \%$ of difference in near correction area covered by different pupil sizes induced in the study. Considering the minimum pupil sizes (baseline) in the study were 3.71, 3.90 and $4.46 \mathrm{~mm}$ for different fixation distances, approximately $50 \%$ of near correction is still placed when looking at the far distance, which caused a reduction in distance VA. However, less than $2 \mathrm{~mm}$ of pupil enlargement in the study during normal lighting conditions may not be enough to induce improvement in VA, similarly to Lanier et al. ${ }^{28}$ Near VA was not affected by ND filters, aside from a clinically insignificant average twoletter reduction with the 0.9 ND filter.

There was a reduction in CS with MTF CL compared to control, and a greater reduction was found when wearing the ND filter. The results agree with findings that CS is reduced with decreased luminance, ${ }^{29}$ as would be the case when wearing ND filters. Studies also pointed out that target discrimination and identification are also affected, ${ }^{30}$ so that reaction time decreased with low luminance. $^{31}$ In addition, detection of pedestrians in a driving simulator could be impaired with reduction of $\mathrm{CS}^{32}$ Therefore, CS should be carefully checked when wearing sunglasses, as CS may be impaired while highcontrast VA could remain unimpaired.

In summary, in a group of adults with early presbyopia, the use of ND filters causing low illuminance and accordingly enlarged pupil size did not improve distance vision when wearing MTF CLs. Furthermore, when transmittance was reduced by $50 \%$ this reduced distance vision and CS. MTF CL designs which incorporate tints, or tints that vary in darkness in response to UV exposure, should consider these findings.

\section{Conclusions}

The results of this study demonstrated that wearing ND filters over MTF CLs was enough to induce pupil size variation. However, pupil size changes induced by tinted lenses may not improve distance vision while wearing MTF CLs under brightly illuminated conditions.

In addition, ND filters with less than $50 \%$ of visible light transmittance have a negative effect on distance VA. Anecdotal suggestions to improve distance by enlarging the pupil when wearing a centre-near design of MTF CL were not supported by the findings of this study. Therefore, adjustment of the prescription should be considered first for improving near or distance VA with MTF CL wear.

\section{Acknowledgment}

This work was supported by research grants from Daegu Catholic University in 2017.

\section{Disclosure}

The authors report no conflicts of interest in this work. 


\section{References}

1. Population pyramids of the world 2019. Available from: https://www. populationpyramid.net/world/2019/. Accessed December 10, 2019.

2. Holden BA, Fricke TR, Ho SM, et al. Global vision impairment due to uncorrected presbyopia. Arch Ophthalmol. 2008;126(12):1731-1739. doi:10.1001/archopht.126.12.1731

3. Miranda MN. The geographic factor in the onset of presbyopia. Trans Am Ophthalmol Soc. 1979;77:603-621.

4. Charman WN. The eye in focus: accommodation and presbyopia. Clin Exp Optom. 2008;91(3):207-225. doi:10.1111/j.1444-0938.2008.00256.x

5. McDonnell PJ, Lee P, Spritzer K, Lindblad AS, Hays RD. Associations of presbyopia with vision-targeted health-related quality of life. Arch Ophthalmol. 2003;121(11):1577-1581. doi:10.1001/ archopht.121.11.1577

6. Chu BS, Wood JM, Collins MJ. The effect of presbyopic vision corrections on nighttime driving performance. Invest Ophthalmol Vis Sci. 2010;51(9):4861-4866. doi:10.1167/iovs.10-5154

7. Nichols JJ. Contact Lenses 2008. Contact Lens Spectrum. 2009;24 (1):24-32.

8. Morgan PB, Tranoudis IG, et al. International contact lens prescribing in 2019. Contact Lens Spectrum. 2020:26-32.

9. Efron N, Nichols JJ, Woods CA, et al. Trends in US contact lens prescribing 2002 to 2014. Optom Vis Sci. 2015;92(7):758-767. doi:10.1097/OPX.0000000000000623

10. Jones D, Woods C, Jones L, et al. A sixteen year survey of Canadian contact lens prescribing. Cont Lens Anterior Eye. 2016;39 (6):402-410. doi:10.1016/j.clae.2016.09.002

11. Bennett ES. Contact lens correction of presbyopia. Clin Exp Optom. 2008;91(3):265-278. doi:10.1111/j.1444-0938.2007.00242.x

12. Koffler BH. Management of presbyopia with soft contact lenses. Ophthalmologica. 2002;216(Suppl 1):34-51. doi:10.1159/000064649

13. Woods J, Woods C, Fonn D. Visual performance of a multifocal contact lens versus monovision in established presbyopes. Optom Vis Sci. 2015;92(2):175-182. doi:10.1097/OPX.0000000000000476

14. Evans BJ. Monovision: a review. Ophthalmic Physiol Opt. 2007;27 (5):417-439. doi:10.1111/j.1475-1313.2007.00488.x

15. Charman WN. Correcting presbyopia: the problem of pupil size. Ophthalmic Physiol Opt. 2017;37(1):1-6. doi:10.1111/opo.2017.37. issue-1

16. Ostin LA, Glasser A. Accommodation measurements in a prepresbyopic and presbyopic population. $J$ Cataract Refract Surg. 2004;30(7):1435-1444. doi:10.1016/j.jcrs.2003.12.045

17. Ravikumar A, Benoit JS, Morrison KB, et al. Repeatability of monocular acuity testing in adults with and without down syndrome. Optom Vis Sci. 2018;95(3):202-211. doi:10.1097/OPX.0000000000001185

18. Kasthurirangan S, Glasser A. Characteristics of pupil responses during far-to-near and near-to-far accommodation. Ophthalmic Physiol Opt. 2005;25(4):328-339. doi:10.1111/opo.2005.25.issue-4
19. Ripps H, Chin NB, Siegel IM. The effect of pupil size on accommodation, convergence, and the $\mathrm{AC} / \mathrm{A}$ ratio. Invest Ophthalmol. 1962;1:127-135.

20. Simmers AJ, Gray LS, Wilkins AJ. The influence of tinted lenses upon ocular accommodation. Vision Res. 2001;41(9):1229-1238. doi:10.1016/S0042-6989(00)00291-1

21. Ciuffreda KJ, Scheiman M, Ong E. Irlen lenses do not improve accommodative accuracy at near. Optom Vis Sci. 1997;74 (5):298-302. doi:10.1097/00006324-199705000-00026

22. Millodot M, Millodot S. Presbyopia correction and the accommodation in reserve. Ophthalmic Physiol Opt. 1989;9(2):126-132. doi:10.1111/opo.1989.9.issue-2

23. Almutairi MS, Altoaimi BH, Bradley A. Accommodation in early presbyopes fit with bilateral or unilateral near add. Optom Vis Sci. 2018;95(1):43-52. doi:10.1097/OPX.0000000000001155

24. The contact lens that knows light TM. Available from: https://www. acuvue.com/acuvue-oasys-transition-contact-lenses. Accessed January 12,2020

25. Hoover H,L. Sunglasses, pupil dilation, and solar ultraviolet irradiation of the human lens and retina. Appl Opt. 1987;26(4):689-695. doi:10.1364/AO.26.000689

26. Guillon M, Maissa C, Cooper P. Visual performance of a multi-zone bifocal and a progressive multifocal contact lens. CLAO J. 2002;28 (2):88-93.

27. Richdale K, Mitchell GL, Zadnik K. Comparison of multifocal and monovision soft contact lens corrections in patients with low-astigmatic presbyopia. Optom Vis Sci. 2006;83(5):266-273. doi:10.1097/01.opx.0000216098.62165.34

28. Lanier K, Conway R, Jaworski A. Visual acuity and contrast sensitivity in multifocal contact lenses through different pupil sizes. Cont Lens Anterior Eye. 2018;41(6):S22. doi:10.1016/j.clae.2018.04.149

29. Hunter M, Godde B, Olk B. Effects of absolute luminance and luminance contrast on visual discrimination in low mesopic environment. Atten Percept Psychophys. 2017;79(1):243-252. doi:10.3758/s13414-016-1219-z

30. Walkey HC, Harlow JA, Barbur JL. Changes in reaction time and search time with background luminance in the mesopic range. Ophthalmic Physiol Opt. 2006;26(3):288-299. doi:10.1111/ opo.2006.26.issue-3

31. Walkey HC, Harlow JA, Barbur JL. Characterising mesopic spectral sensitivity from reaction times. Vis Res. 2006;46(25):4232-4243. doi:10.1016/j.visres.2006.08.002

32. Swan G, Shahin M, Albert J. The effects of simulated acuity and contrast sensitivity impairments on detection of pedestrian hazards in a driving simulator. Transp Res Part F Traffic Psychol Behav. 2019;64:213-226. doi:10.1016/j.trf.2019.05.003
Clinical Optometry

\section{Publish your work in this journal}

Clinical Optometry is an international, peer-reviewed, open access journal publishing original research, basic science, clinical and epidemiological studies, reviews and evaluations on clinical optometry. All aspects of patient care are addressed within the journal as well as the practice of optometry including economic and business analyses. Basic and clinical research papers are published that cover

Submit your manuscript here: https://www.dovepress.com/clinical-optometry-journal all aspects of optics, refraction and its application to the theory and practice of optometry. The manuscript management system is completely online and includes a very quick and fair peer-review system, which is all easy to use. Visit http://www.dovepress.com/ testimonials.php to read real quotes from published authors. 